\title{
Increased peroxisome proliferator-activated receptor $\gamma$ expression levels in visceral adipose tissue, and serum CCL2 and interleukin-6 levels during visceral adipose tissue accumulation
}

\author{
THANESWARY YOGARAJAH ${ }^{1}$, YVONNE-TEE GET BEE ${ }^{2}$, RAHMAH NOORDIN ${ }^{1}$ and KHOO BOON YIN ${ }^{1}$ \\ ${ }^{1}$ Institute for Research in Molecular Medicine (INFORMM), Universiti Sains Malaysia, 11800 Penang; \\ ${ }^{2}$ School of Health Sciences, Universiti Sains Malaysia, 16150 Kubang Kerian, Kelantan, Malaysia
}

Received November 13, 2013; Accepted June 5, 2014

DOI: $10.3892 / \mathrm{mmr} .2014 .2686$

\begin{abstract}
This study was conducted to determine the mRNA and protein expression levels of peroxisome proliferator-activated receptors (PPARs) in visceral adipose tissue, as well as serum adipokine levels, in Sprague Dawley rats. The rats were fed either a normal (control rats) or excessive (experimental rats) intake of food for 8 or 16 weeks, then sacrificed, at which time visceral and subcutaneous adipose tissues, as well as blood samples, were collected. The mRNA and protein expression levels of PPARs in the visceral adipose tissues were determined using reverse transcription-polymerase chain reaction and Western blotting, respectively. In addition, the levels of adipokines in the serum samples were determined using commercial ELISA kits. The results revealed that at 8 weeks, the mass of subcutaneous adipose tissue was higher than that of the visceral adipose tissue in the experimental rats, but the reverse occurred at 16 weeks. Furthermore, at 16 weeks the experimental rats exhibited an upregulation of PPAR $\gamma$ mRNA and protein expression levels in the visceral adipose tissues, and significant increases in the serum levels of CCL2 and interleukin (IL)-6 were observed, compared with those measured at 8 weeks. In conclusion, this study demonstrated that the PPAR $\gamma$ expression level was likely correlated with serum levels of CCL2 and IL-6, molecules that may facilitate visceral adipose tissue accumulation. In addition, the levels of the two adipokines in the serum may be useful as surrogate biomarkers for the expression levels of PPAR $\gamma$ in accumulated visceral adipose tissues.
\end{abstract}

Correspondence to: Dr Khoo Boon Yin, INFORMM, Universiti Sains Malaysia, H53 Jalan Inovasi, Minden, 11800 Penang, Malaysia E-mail: boonyin@usm.my; kboonyin@yahoo.com

Key words: peroxisome proliferator-activated receptor $\gamma$, CCL2, interleukin-6, excessive feeding, visceral adipose tissue

\section{Introduction}

Adipose tissue is an active metabolic and endocrine organ that secretes adipokines acting locally or peripherally to influence multiple biological processes, including glucose and fatty acid metabolism, insulin sensitivity, adipocyte differentiation, inflammation and immunity (1). The adipose tissue that accumulates in the body is classified into two categories: subcutaneous adipose tissue, which is stored under the skin, and visceral adipose tissue, which is stored in or surrounding the internal organs $(2,3)$. Excess visceral adipose tissue may result in serious health problems as it surrounds the vital organs and is metabolised by the liver into cholesterol. Accumulation of the two types of adipose tissues may be age-related and the accumulation of visceral adipose tissue has been demonstrated to increase with age (4). The visceral adipose tissue and the adipokines secreted by this tissue appear to be key components that determine and predict the development of numerous visceral adipose tissue-related diseases.

Excessive accumulation of visceral adipose tissues in humans is associated with various chronic diseases, including type II diabetes, high blood pressure, hypertension, dyslipidemia, various types of cancer and cardiovascular diseases $(5,6)$. Evidence has suggested that the excessive accumulation of adipose tissue alters the secretion of adipokines, including leptin, interleukin (IL)-6, resistin, CCL2, adiponectin and tumour necrosis factor (TNF)- $\alpha$, which promote proliferation, angiogenesis and invasion in certain types of cancer (7). Changes in the adipokine levels affect cell proliferation, apoptosis and invasive growth of cancer cells (8). The adipokines produced by visceral adipose tissue have been shown to be associated with the risk and the progression of breast cancer $(9,10)$. Therefore, elucidating the genes that regulate visceral adipose tissue accumulation and the adipokine network is important to understand the progression of visceral adipose tissue-related diseases further. This research may result in the development of novel therapies to regulate the secretion of adipokines involved in disease pathogenesis, and the identification of potential biomarkers for the detection and prevention of the visceral adipose tissue-related diseases.

A number of studies have been conducted to understand the general mechanisms that regulate alterations in adipose tissue mass. However, the mechanism underlying visceral adipose 
tissue accumulation remains unclear. Therefore, the present study investigated the gene expression profiles in accumulated visceral adipose tissues and the levels of adipokines in serum samples, using an animal model. The aim was to identify the molecular targets that facilitate excessive visceral adipose tissue accumulation. The focus was on peroxisome proliferator-activated receptors (PPARs) since these genes are key mediators in adipogenesis and regulate the adipokine network (11). Following an excessive feeding regimen for 8 and 16 weeks, the expression levels of PPAR mRNA and protein in visceral adipose tissue were analysed using reverse transcription-polymerase chain reaction (RT-PCR) and Western blotting, respectively. In addition, the levels of adipokines in the sera of the animals were determined using ELISA.

\section{Materials and methods}

Animal feeding, serum and adipose tissue collection. The use of animals was approved by the Research Ethics (Animal) Committee, Universiti Sains Malaysia (Penang, Malaysia). Male Sprague Dawley rats (weight, 80-100 g; age, 4 weeks) were obtained from the Animal House of the Universiti Sains Malaysia (Kubang Kerian, Kelantan, Malaysia). The rats were randomly assigned to two groups: Six control rats were fed a normal intake of food ( $5 \mathrm{~g}$ pellet/100 $\mathrm{g}$ body weight per day) and six experimental rats were fed an excessive intake of food (10 g pellet/100 g body weight per day). The animal feed was obtained from Gold Coin Feedmills Sdn. Bhd (Penang, Malaysia). The rats were provided pre-weighed quantities of food each day and the quantity remaining in the food dish was weighed every $24 \mathrm{~h}$. The body weight of each rat was measured weekly to determine growth. A total of four groups were used, with six rats in the 8 week group (three control rats; three experimental rats) and six in the 16 week group (three control rats; three experimental rats). The experiment was repeated twice. Following a feeding period of 8 weeks, the waist circumferences of the three rats in each group were measured prior to sacrifice via brief exposure to $10 \%$ (v/v) diethyl ether in a chamber. The same measurement was peformed prior to sacrifice in the three rats in each of the two 16 week feeding period groups. Blood was also collected from the rats in each group following the feeding periods of 8 and 16 weeks by cardiac puncture, left to clot and centrifuged at $3,000 \mathrm{x} \mathrm{g}$ for $15 \mathrm{mins}$ to obtain serum for ELISA. For long-term storage, the serum samples were maintained at $-80^{\circ} \mathrm{C}$. The adipose tissues (visceral and subcutaneous) were collected and weighed. The visceral adipose tissues were used for total RNA extraction or rinsed in TRI Reagent ${ }^{\circledR}$ (Molecular Research Center, Inc., Cincinnati, OH, USA), frozen in liquid nitrogen and stored at $-80^{\circ} \mathrm{C}$ until use.

Total RNA extraction and cDNA synthesis. Total RNA extraction was performed using the TRI Reagent ${ }^{\circledR}$, according to the manufacturer's instructions. For this, total RNA was extracted from the aqueous phase (colourless top layer) of the homogenised tissue samples and the remaining organic phase was stored at $-80^{\circ} \mathrm{C}$ for subsequent protein extraction. The integrity of the total RNA extracted was confirmed using agarose gel electrophoresis, while the purity and yield of the RNA were measured using a nanophotometer (Implen, München,
Table I. Primers used for RT-PCR amplification.

\begin{tabular}{llc} 
Gene & \multicolumn{1}{c}{ Primer sequences } & $\begin{array}{c}\text { Amplicon } \\
\text { (bp) }\end{array}$ \\
\hline PPARa & F: 5'-TGGAGTCCACGCATGTGAAG-3' & 72 \\
& R: 5'-TTGTCGTACGCCAGCTTTAGC-3' & \\
PPARd & F: 5'-CATGAGTTCTTGCGCAGTATCC-3' & 83 \\
& R: 5'-AGAGCATTGAACTTGACAGCAAAC-3' & \\
PPAR $\gamma$ & F: 5'-CATGACCAGGGAGTTCCTCAA-3' & 73 \\
& R: 5'-AGCAAACTCAAACTTAGGCTCCAT-3' & \\
GAPDH & F: 5'-CAAGTTCAA CGGCACAGTCAAG-3' & 76 \\
& R: 5'-CTCCTGGAAGATGGTGATTGGT-3' & \\
\hline
\end{tabular}

RT-PCR, reverse transcription-polymerase chain reaction; PPAR, peroxisome proliferator-activated receptor; $\mathrm{F}$, forward; $\mathrm{R}$, reverse.

Germany). Subsequently, $1 \mu \mathrm{g}$ total RNA was reverse-transcribed to cDNA using the RevertAid ${ }^{\mathrm{TM}}$ First Strand cDNA Synthesis kit (Fermentas, Waltham, MA, USA), according to the manufacturer's instructions. The success of cDNA synthesis was validated by conventional PCR using rat GAPDH primers. The sequences of the GAPDH and PPAR primers used in the present study are listed in Table I.

Determination of PPAR expression levels. Following cDNA synthesis, the PPAR expression levels were determined using 2X Power SYBR Green PCR master mix (Applied Biosystems, Inc., Foster City, CA, USA) in a Rotor-Gene 6000 PCR machine (Qiagen, Hilden, Germany). The final concentrations of cDNA and each primer used were $5 \mathrm{ng} / \mu \mathrm{l}$ and $0.4 \mu \mathrm{M}$, respectively. The GAPDH gene served as a reference gene, to compare the expression levels amongst different samples. All primers were designed with an annealing temperature of $55^{\circ} \mathrm{C}$ using the Primer Express 2.0 software (Applied Biosystems, Inc.). All PCR reactions were performed at $94^{\circ} \mathrm{C}$ for $10 \mathrm{~min}$ followed by 40 cycles of denaturation at $94^{\circ} \mathrm{C}$ for $20 \mathrm{sec}$, primer annealing at $55^{\circ} \mathrm{C}$ for $20 \mathrm{sec}$ and extension at $72^{\circ} \mathrm{C}$ for $30 \mathrm{sec}$. A dissociation curve program was added following the completion of the reaction in order to generate the derivative dissociation curve. The derivative dissociation curve was created to confirm the primer-dimer artifact and to ensure the RT-qPCR specificity. The dissociation curve program was conducted at $95^{\circ} \mathrm{C}$ for $90 \mathrm{sec}$ and $72^{\circ} \mathrm{C}$ to $95^{\circ} \mathrm{C}$ at $1^{\circ} \mathrm{C} / 5 \mathrm{sec}\left(1^{\circ} \mathrm{C}\right.$ increase every $5 \mathrm{sec}$ between 72 and $95^{\circ} \mathrm{C}$ ) using the same PCR machine. Each PCR reaction was performed as three replicates in two independent experiments. The PPAR gene expression levels were determined using the relative quantification approach. The $2^{(-\Delta \Delta \mathrm{Ct})}$ method was used to analyse relative change in gene expression level (12). The value for fold-change in gene expression level was calculated as determined by the target gene expression level versus the reference gene expression level.

Protein extraction. The total protein from visceral adipose tissue was extracted from the organic phase of the samples as described above. The protein concentration was determined using the DC Protein Assay kit (Bio-Rad, Hercules, CA, USA) and then used for Western blot analysis. 


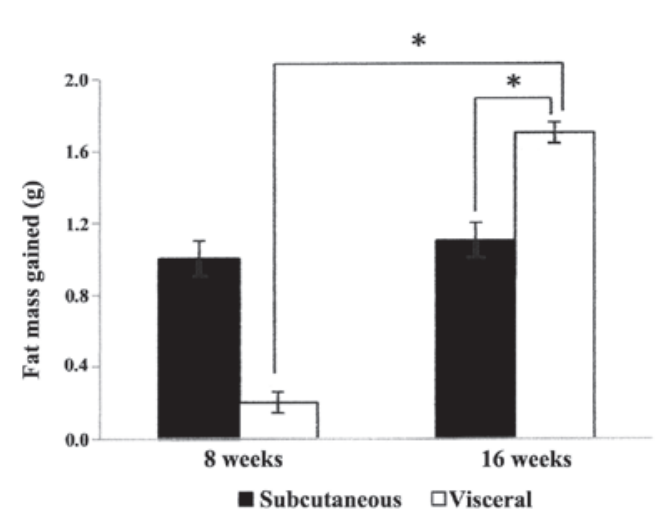

Figure 1. Accumulation of visceral and subcutaneous adipose tissue masses in Sprague Dawley rats after 8 and 16 weeks excessive food intake. The increase in adipose tissue mass was calculated as the average adipose tissue mass of experimental rats minus the average adipose tissue mass of control rats. Values are expressed as the mean \pm standard deviation of three rats per growth stage. Student's t-test was used to compare the group means. ${ }^{*} \mathrm{P}<0.05$, compared with the same or different type of adipose tissue mass at the same or different growth stage.

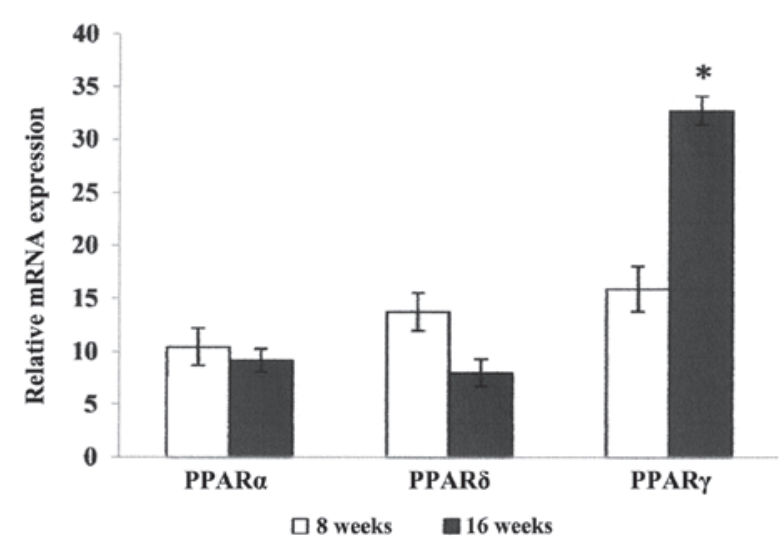

Figure 2. mRNA expression levels of peroxisome proliferator-activated receptors (PPARs) in visceral adipose tissues of male Sprague Dawley rats with excessive food intake for 8 and 16 weeks. All values are presented as the mean \pm standard deviation of three rats per growth stage. One-way analysis of variance was calculated. "P $<0.05$, compared with the 8 weeks group.

Western blot analysis. The protein samples (30 $\mu \mathrm{g}$ per well) were separated on a $10 \%$ SDS-polyacrylamide gel. The samples were then electrophoretically transferred to a nitrocellulose membrane, then blocked using 5\% skimmed milk powder for $60 \mathrm{~min}$ at room temperature with constant agitation. The membrane was washed three times for 10 min each using 1X Tris-buffered saline and Tween-20, and then incubated with 1:250 responsive primary rabbit polyclonal antibody for PPAR $\alpha$ (H-98: sc-9000), PPARס (H-74: sc-7197) and PPAR $\gamma$ (H-100: sc-7196) at $4^{\circ} \mathrm{C}$, overnight. All antibodies were obtained from Santa Cruz Biotechnology, Inc. (Santa Cruz, CA, USA). Subsequent to washing, the membrane was incubated at room temperature for $1 \mathrm{~h}$ with 1:5,000 horseradish peroxidase-conjugated rat anti-rabbit antibody (Santa Cruz Biotechnology, Inc.). Subsequent to another washing step, the blot was incubated with the SuperSignal West Pico Chemiluminescent Substrate (Pierce Biotechnology, Inc., Rockford, IL, USA). The blot was then developed on film in a dark room. Anti-rabbit GAPDH antibody
(Santa Cruz Biotechnology, Inc.) was used as a control, to verify equal sample loading.

Determination of adipokine expression levels. The expression levels of the CCL2, TNF- $\alpha$, adiponectin, leptin, resistin, IL-6 adipokines and C-reactive protein (CRP; control) in the serum samples of control and experimental rats, were determined using commercially available ELISA kits (Abnova, Taipei, Taiwan). In these kits, antibodies specific for the adipokines had been pre-coated onto 96 -well microtitre plates. The serum samples were then added to the wells and allowed to react with the bound antibody for $2.5 \mathrm{~h}$ at room temperature. The unbound antibodies were washed away with a Wash Solution, according to the manufacturer's instructions. Subsequently, an enzymelinked antibody specific to the adipokine was added to the wells. The antibody was incubated with the targeted protein for $1 \mathrm{~h}$. Following another washing step, a substrate solution was added to the wells for colour development. The colour developed was proportional to the quantity of adipokine present in the samples. The colour intensity was then measured using an ELISA reader (Tecan Group, Ltd., Männedorf, Switzerland) at a wavelength of $450 \mathrm{~nm}$ and the level of each adipokine in the serum samples was calculated. The ELISAs were performed in triplicate and repeated in two independent experiments.

Statistical analysis. All graphs and statistical analyses were performed using the GraphPad Prism5 software (GraphPad Software Inc., La Jolla, CA, USA). All values are expressed as the mean \pm standard deviation. Student's t-test was used to compare the means of two groups and one way analysis of variance (ANOVA) was used to compare the means between the groups. $\mathrm{P}<0.05$ was considered to indicate a statistically significant difference.

\section{Results}

Weight gain. The results demonstrated that weight gain increased with time and that the rats in the experimental group, which consumed more food, gained more weight compared with the rats in the control group. The weight gain reached a plateau phase at a feeding period of 14 weeks, whereby the weights of the control and experimental rats were $\sim 325$ and $400 \mathrm{~g}$, respectively. However, following feeding periods of 14 weeks, no more weight gain was observed in either the control or the experimental rats. In the experimental rats (fed with excessive food intake), the accumulation of adipose tissue mass was first observed at 8 weeks.

Adipose tissue mass. In the experimental rats (fed with excessive food intake), the accumulation of adipose tissue mass was first observed at 8 weeks. The subcutaneous adipose tissue mass collected was higher than the visceral adipose tissue mass (Fig. 1). At 16 weeks, the quantity of subcutaneous adipose tissue mass in the experimental rats was unchanged as compared with the fat mass at 8 weeks. However, the accumulation of visceral adipose tissue mass was significantly increased $(\mathrm{P}<0.05)$ in the experimental rats at 16 weeks, when compared with the fat mass at 8 weeks. The visceral adipose tissue mass in the experimental rats was also significantly higher than the mass of the subcutaneous adipose tissue $(\mathrm{P}<0.05)$ at 16 weeks. 

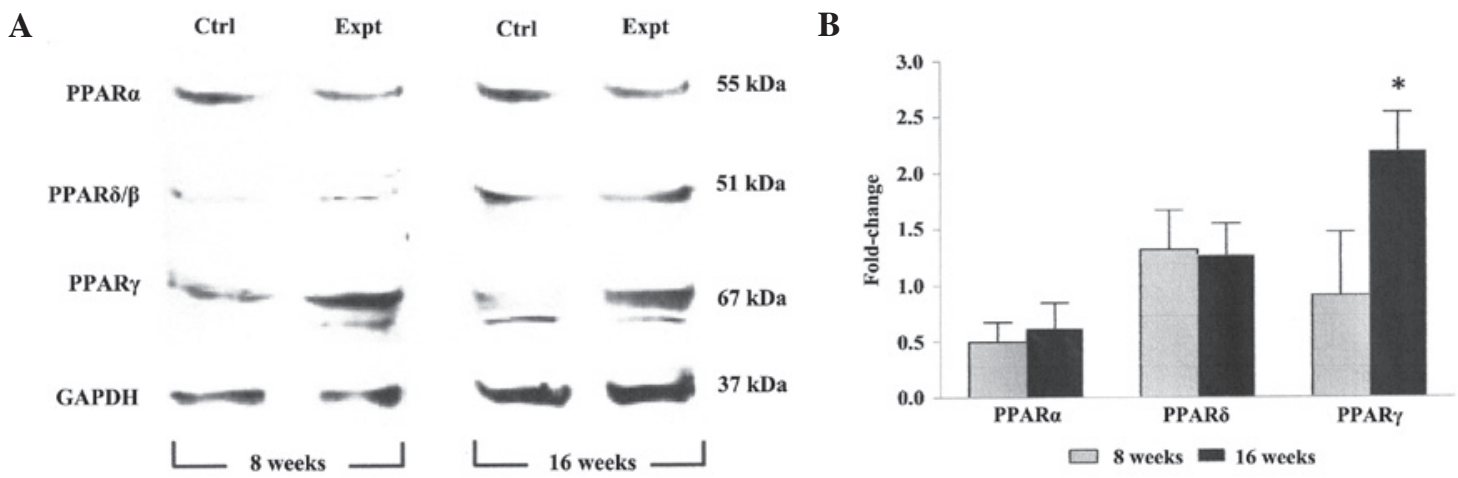

Figure 3. Peroxisome proliferator-activated receptor (PPAR) protein expression levels in visceral adipose tissue of male Sprague Dawley rats with excessive food intake for 8 and 16 weeks (Expt), compared with control rats with a normal food intake (Ctrl). Protein expression levels were analysed by (A) Western blotting and (B) densitometry. The membranes were incubated with antibody directed against GAPDH as a control for equal protein loading. ${ }^{*} \mathrm{P}<0.05$, compared with the respective control group at the same time point.

A

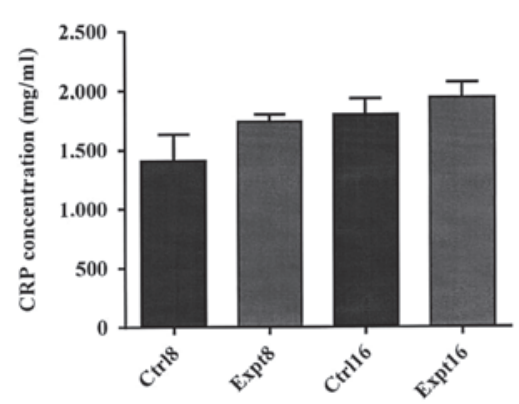

B

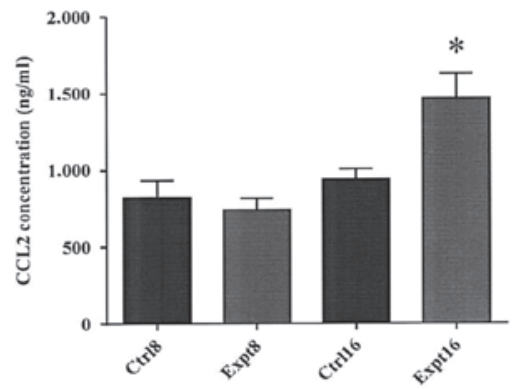

C

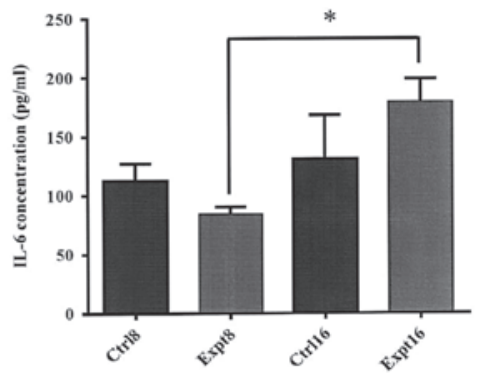

D

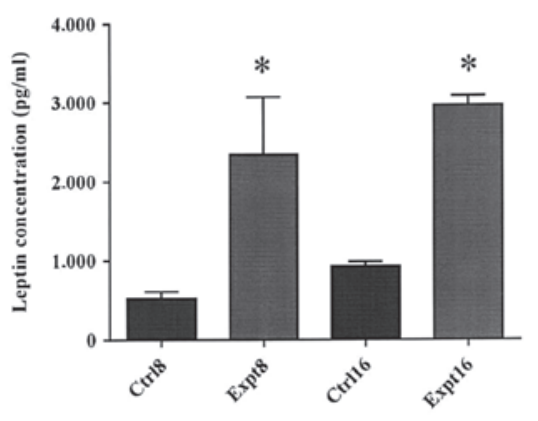

$\mathbf{F}$

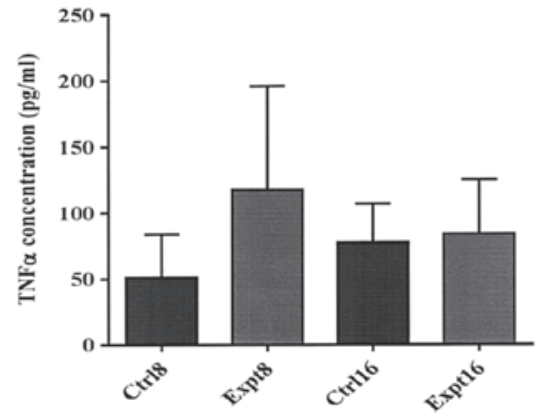

E

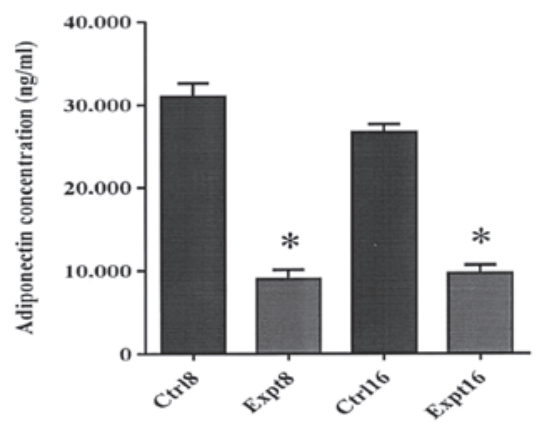

G

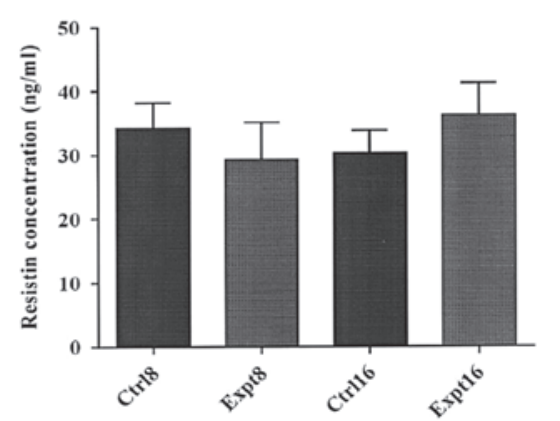

Figure 4. Levels of (A) C-reactive protein (CRP; control), (B) CCL2, (C) interluekin (IL)-6, (D) leptin, (E) adiponectin, (F) tumour necrosis factor (TNF)- $\alpha$, and (G) resistin in rat serum samples. The serum samples were collected at 8 and 16 weeks from control (Ctrl) rats with a normal food intake and experimental (Expt) rats with excessive food intake. The data are presented as mean \pm standard deviation. Student's t-test was performed. ${ }^{*}<0.05$, compared with the respective control group.

Expression levels of PPARs in visceral adipose tissue of rats on an excessive feeding regimen. The PCR results detected no significant difference $(\mathrm{P}>0.05)$ in the PPAR $\alpha$ and PPAR $\delta$ mRNA expression levels in the visceral adipose tissue between samples obtained at 8 and 16 weeks (Fig. 2). Conversely, at 16 weeks, the experimental rats exhibited a significant increase $(\mathrm{P}<0.05$; $\sim 2$-fold) in the mRNA expression level of PPAR $\gamma$ relative to the result obtained at 8 weeks. A similar pattern in the protein 
expression levels of all PPARs, as assessed by Western blotting, was observed in the visceral adipose tissue of experimental rats at 8 and 16 weeks (Fig. 3).

Levels of adipokines in the sera of rats on an excessive feeding regimen. As shown in Fig. 4, no significant differences $(\mathrm{P}>0.05)$ were observed in the levels of CCL2 and IL-6 in serum samples between experimental and control rats at 8 weeks. However, at 16 weeks, significantly higher levels of CCL2 $(\mathrm{P}<0.05)$ were detected in the serum samples of the experimental rats $(1,465 \mathrm{ng} / \mathrm{ml})$, compared with those of the control rats (939.8 ng/ml; Fig. 4B). In addition, at 16 weeks, the levels of IL-6 in the experimental rats $(179.1 \mathrm{pg} / \mathrm{ml})$ were significantly higher $(\mathrm{P}<0.05)$, when compared with those at 8 weeks $(84.3 \mathrm{pg} / \mathrm{ml}$; Fig. 4C). The levels of leptin at 8 weeks were found to be significantly increased $(\mathrm{P}<0.05)$ in the serum samples of experimental rats $(2,341 \mathrm{pg} / \mathrm{ml})$, compared with those of the control rats (526.7 pg/ml). This phenomenon was also observed at 16 weeks, with $2,971 \mathrm{pg} / \mathrm{ml}$ in experimental rats and $928.9 \mathrm{pg} / \mathrm{ml}$ in control rats $(\mathrm{P}<0.05$; Fig. 4D). Conversely, significantly reduced levels of adiponectin $(\mathrm{P}<0.05)$ were observed in the serum samples of experimental rats compared with the control rats at 8 and 16 weeks (Fig. 4E). No significant differences were identified in the levels of the resistin and TNF- $\alpha$ between experimental and control rats in all serum samples (Fig. 4F and G).

\section{Discussion}

In a previous study, female rats fed an excessive food intake developed more mesenteric adipose tissue compared with male rats (13). However, the female rats were able to oxidise the tissue faster, thus male rats were considered to exhibit a higher tendency towards obesity-related diseases. Therefore, in the present study, only male rats were used. An increase in the visceral adipose tissue mass was observed in the Sprague Dawley experimental rats with excessive food intake for 16 weeks. An increase in the expression levels of PPAR $\gamma$ mRNA and protein were also detected in the visceral adipose tissue of experimental rats, along with increased levels of CCL2 and IL-6 in the sera. These increases were correlated with increased accumulation of visceral adipose tissue in the rats.

In the majority of previously reported studies, a high fat diet was used to analyse weight gain and adipose tissue accumulation in the animals $(14,15)$. However, in the present study, accumulation of subcutaneous and visceral adipose tissues was investigated via excessive food intake. Nevertheless, similar results were obtained, in which weight gain and accumulation of adipose tissue in the rats with excessive food intake was observed. Weight gain and an increase in subcutaneous adipose tissue was observed in the experimental rats at 8 weeks. After 8 weeks of the feeding regimen, marginal weight gain was observed in the experimental rats, despite an increase in visceral adipose tissue. This phenomenon suggests that accumulation of visceral adipose tissue at 16 weeks may be independent of weight gain.

At the molecular level, the expression levels of PPARs were analysed to identify the genes associated with visceral adipose tissue accumulation. The PPAR $\gamma$ expression level exhibited a positive correlation with the expression levels of genes involved in the formation of visceral fat deposits following excessive food intake for 16 weeks. However, the expression levels of PPAR $\alpha$ and PPAR $\delta$ in the visceral adipose tissues collected from the rats of experiment and control groups, at 8 and 16 weeks, were not identified to be significantly different in the present study. Thus, this finding reveals the important role of PPAR $\gamma$ in visceral adipose tissue accumulation. Furthermore, the PPAR $\gamma$ mRNA and protein expression levels were found to correlate with visceral adipose tissue accumulation at the later phase (16 weeks) of the adipose tissue development. PPAR $\gamma$ is predominant in the regulation of adipocyte proliferation, lipid accumulation and specific adipocyte biomarker expression (16). A study conducted by Duffield et al (17) demonstrated that early change in the PPAR $\gamma$ expression level in the visceral adipose tissue of lambs results in obesity in later life. This may be due to PPAR $\gamma$ activation, which enhances hyperplasia in adipocytes and results in greater accumulation of adipose tissue in the body. PPAR $\gamma$ has also been reported to activate other factors involved in regulating the development of adipose tissue (18). When PPAR $\gamma$ is upregulated due to a high-fat diet, other adipocyte differentiation-related genes, such as aP2 and $\mathrm{C} / \mathrm{EBP} \alpha$, are also overexpressed (18). Omentum fat accumulation also exhibits a correlation with the expression levels of PPAR $\gamma$ (19), which is consistent with the findings of the present study. Furthermore, PPAR $\gamma$-knockout mice were unable to survive due to the inhibition of adipogenesis (21). The PPAR $\gamma$ gene has also been reported to be involved in the pathogenesis of numerous other diseases, such as type 2 diabetes, glomerulosclerosis and several types of cancer (21-23).

Adipocytes are known to secrete a large number of growth hormones, growth factors, enzymes, cytokines, complement factors and matrix proteins, which are indirectly correlated with obesity (24). The expression of PPAR $\gamma$ in adipose tissue is considered to induce the production of various enzymes and proteins responsible for the activation of soluble factors, including adipokines and growth hormones, which are detectable in the serum (25). In the present study, the results revealed that the expression levels of PPAR $\gamma$ in visceral adipose tissue may be correlated with upregulation of serum CCL2 and IL-6. Upregulation of serum leptin and downregulation of serum adiponectin were also observed in the experimental rats. However, the levels of these adipokines may be associated with adipose tissue accumulation in general and not specifically with the accumulation of visceral adipose tissue.

CCL2 is an important cytokine that has been associated with adipose tissue-related diseases $(26,27)$. In the present study, the level of serum CCL2 increased in rats with accumulated visceral adipose tissue. A similar finding was reported in a study conducted by Chen et al (28) who revealed that CCL2/monocyte chemoattractant proteins-1 and -3 were elevated in mice administered a high-fat diet for 4 weeks, and this phenomenom was ascribed to systemic inflammation. A study by Park et al (29) demonstrated correlations among serum levels of CRP, IL- 6 and TNF- $\alpha$, obesity and visceral adiposity. Significant correlations were observed between concentrations of serum CRP and IL- 6 and visceral adiposity, while concentrations of TNF- $\alpha$ exhibited a significant correlation with weight, body-mass index and waist circumference. Notably, the findings of the present study revealed that serum CCL2 and IL-6 levels were increased in rats with visceral adipose tissue accumulation following excessive food intake, which is in concordance with 
the results of a number of these previous studies. However, no significance differences were identified in the levels of TNF- $\alpha$ amongst all serum samples. A large number of studies have demonstrated that CCL2 and IL-6 facilitate tumour progression in pancreatic (30), breast $(31,32)$ and gastric cancer (33). Thus, CCL2 and IL- 6 are potential molecular targets that indicate the expression level of PPAR $\gamma$ in visceral adipose tissue as well as the accumulation of visceral adipose tissue in the body.

In conclusion, accumulation of visceral adipose tissue mass was observed in rats after 16 weeks of an excessive feeding regimen and the expression level of PPAR $\gamma$ may have facilitated the process of visceral adipose tissue accumulation. The increase of PPAR $\gamma$ expression in visceral adipose tissue was correlated with increased levels of CCL2 and IL-6 in the serum. The CCL2 and IL-6, which are easily detected in the serum, are thus potential surrogate biomarkers for the level of PPAR $\gamma$ expression in accumulated visceral adipose tissue. This may have applications for the development of novel diagnostic and therapeutic strategies to address visceral adipose tissue-related diseases. However, further in-depth confirmatory studies are required in the near future.

\section{Acknowledgements}

This study was funded by a Fundamental Research Grant Scheme Fasa 1/2008 (grant no. 203/CIPPM/6711119) from the Ministry of Higher Education and the Postgraduate Research Grant Scheme (grant no. 1001/CIPPM/834092) from the Universiti Sains Malaysia. Ms. Thaneswary was supported by a Universiti Sains Malaysia fellowship from the Institute of Postgraduate Studies. The authors would also like to thank the staff at the Genomic Laboratory of the Institute for Research in Molecular Medicine for their technical support.

\section{References}

1. Balistreri CR, Caruso C and Candore G: The role of adipose tissue and adipokines in obesity-related inflammatory diseases. Mediators Inflamm 2010: 802078, 2010.

2. Mårin $\mathrm{P}$, Andersson $\mathrm{B}$, Ottosson $\mathrm{M}$, et al: The morphology and metabolism of intraabdominal adipose tissue in men. Metabolism 41: 1242-1248, 1992.

3. Wajchenberg BL: Subcutaneous and visceral adipose tissue: their relation to the metabolic syndrome. Endocr Rev 21: 697-738, 2000

4. Pascot A, Lemieux S, Lemieux I, et al: Age-related increase in visceral adipose tissue and body fat and the metabolic risk profile of premenopausal women. Diabetes Care 22: 1471-1478, 1999.

5. Sharma AM and Staels B: Review: Peroxisome proliferator-activated receptor gamma and adipose tissue - understanding obesity-related changes in regulation of lipid and glucose metabolism. J Clin Endocrinol Metab 92: 386-395, 2007.

6. Fusco R, Galgani M, Procaccini C, et al: Cellular and molecular crosstalk between leptin receptor and estrogen receptor-\{alpha\} in breast cancer: molecular basis for a novel therapeutic setting. Endocr Relat Cancer 17: 373-382, 2010.

7. Hlavna M, Kohut L, Lipkova J, et al: Relationship of resistin levels with endometrial cancer risk. Neoplasma 58: 124-128,2011.

8. Masaki T and Yoshimatsu H: Obesity, adipokines and cancer. Transl Oncogenomics 3: 45-52, 2008.

9. Nyante SJ, Gammon MD, Kaufman JS, et al: Common genetic variation in adiponectin, leptin, and leptin receptor and association with breast cancer subtypes. Breast Cancer Res Treat 129: 593-606, 2011.

10. Kim SH, Nagalingam A, Saxena NK, Singh SV and Sharma D: Benzyl isothiocyanate inhibits oncogenic actions of leptin in human breast cancer cells by suppressing activation of signal transducer and activator of transcription 3. Carcinogenesis 32: 359-367, 2011.
11. Carter JC and Church FC: Obesity and breast cancer: the roles of peroxisome proliferator-activated receptor- $\gamma$ and plasminogen activator inhibitor-1. PPAR Res 2009: 345320, 2009.

12. Livak KJ and Schmittgen TD: Analysis of relative gene expression data using real-time quantitative PCR and the 2(-Delta Delta C(T)) Method. Methods 25: 402-408, 2001.

13. Priego T, Sánchez J, Picó C and Palou A: Sex-differential expression of metabolism-related genes in response to a high-fat diet. Obesity (Silver Spring) 16: 819-826, 2008.

14. Nomaguchi K, Tanaka M, Misawa E, et al: Aloe vera phytosterols act as ligands for PPAR and improve the expression levels of PPAR target genes in the livers of mice with diet-induced obesity. Obes Res Clin Pract 5: e169-e266, 2011.

15. Kavanagh K, Jones KL, Sawyer J, et al: Trans fat diet induces abdominal obesity and changes in insulin sensitivity in monkeys. Obesity (Silver Spring) 15: 1675-1684, 2007.

16. Hamdy O, Porramatikul S and Al-Ozairi E: Metabolic obesity: the paradox between visceral and subcutaneous fat. Curr Diabetes Rev 2: 367-373, 2006.

17. Duffield JA, Vuocolo T, Tellam R, et al: Intrauterine growth restriction and the sex specific programming of leptin and peroxisome proliferator-activated receptor gamma (PPARgamma) mRNA expression in visceral fat in the lamb. Pediatr Res 66: 59-65, 2009.

18. Dewulf EM, Cani PD, Neyrinck AM, et al: Inulin-type fructans with prebiotic properties counteract GPR43 overexpression and PPARgamma-related adipogenesis in the white adipose tissue of high-fat diet-fed mice. J Nutr Biochem 22: 712-722, 2011.

19. Arai K, Soga T, Ohata H, Otagiri A and Shibasaki T: Effects of food restriction on peroxisome proliferator-activated receptor-gamma and glucocorticoid receptor signaling in adipose tissues of normal rats. Metabolism 53: 28-36, 2004.

20. Barak Y and Kim S: Genetic manipulations of PPARs: effects on obesity and metabolic disease. PPAR Res 2007: 12781, 2007.

21. Nicholas SB, Kawano Y, Wakino S, Collins AR and Hsueh WA: Expression and function of peroxisome proliferator-activated receptor-gamma in mesangial cells. Hypertension 37: 722-727, 2001.

22. Larsen TM, Toubro S and Astrup A: PPARgamma agonists in the treatment of type II diabetes: is increased fatness commensurate with long-term efficacy? Int J Obes Relat Metab Disord 27: 147-161, 2003.

23. Lehrke M and Lazar MA: The many faces of PPARgamma. Cell 123: 993-999, 2005.

24. Frühbeck $\mathrm{G}$ and Salvador J: Role of adipocy tokines in metabolism and disease. Nutr Res 24: 803-826, 2004.

25. Tontonoz P and Spiegelman BM: Fat and beyond: the diverse biology of PPARgamma. Annu Rev Biochem 77: 289-312, 2008.

26. Malavazos AE, Cereda E, Morricone L, et al: Monocyte chemoattractant protein 1: a possible link between visceral adipose tissue-associated inflammation and subclinical echocardiographic abnormalities in uncomplicated obesity. Eur J Endocrinol 153: 871-877, 2005

27. Huber J, Kiefer FW, Zeyda M, et al: CC chemokine and $\mathrm{CC}$ chemokine receptor profiles in visceral and subcutaneous adipose tissue are altered in human obesity. J Clin Endocrinol Metab 93: 3215-3221, 2008.

28. Chen A, Mumick S, Zhang C, et al: Diet induction of monocyte chemoattractant protein-1 and its impact on obesity. Obes Res 13: 1311-1320, 2005.

29. Park HS, Park JY and Yu R: Relationship of obesity and visceral adiposity with serum concentrations of CRP, TNF-alpha and IL-6. Diabetes Res Clin Pract 69: 29-35, 2005.

30. Monti P, Leone BE, Marchesi F, et al: The CC chemokine $\mathrm{MCP}-1 / \mathrm{CCL} 2$ in pancreatic cancer progression: regulation of expression and potential mechanisms of antimalignant activity. Cancer Res 63: 7451-7461, 2003.

31. Ueno T, Toi M, et al: Significance of macrophage chemoattractant protein-1 in macrophage recruitment, angiogenesis, and survival in human breast cancer. Clin Cancer Res 6: 3282$3289,2000$.

32. Saji H, Koike M, Yamori T, et al: Significant correlation of monocyte chemoattractant protein-1 expression with neovascularization and progression of breast carcinoma. Cancer 92: 1085-1091, 2001.

33. Ohta M, Kitadai Y, Tanaka S, et al: Monocyte chemoattractant protein-1 expression correlates with macrophage infiltration and tumor vascularity in human gastric carcinomas. Int J Oncol 22: 773-778, 2003. 